Background: Rheumatoid arth ritis (RA) is an autoimmune disease with progressive activity. The RA remission was observed in women during pregnancy, but the mechanism responsible for remission is hypothetical only and concerns mechanisms of immune regulation such as lymphocyte subpopulations and in terleukin production.

Aims: The lymphocyte subpopulations and interleukin production in vitro in a group of healthy nonpregnant women, healthy pregnantwomen and pregnant women suffering from RA may help towards a better understanding of regulation of the immune processes.

Methods: The investigations were performed in trimester III - 2 days after delivery and 6 weeks after delivery. Peripheral blood lym phocytes were isolated on Gradisol gradient and analysed immediately or after having been cultured for 72 hours in RPMI medium supplemented with $10 \%$ FCS. The cultures were terminated after $72 \mathrm{~h}$, supernatants stored at $-72^{\circ} \mathrm{C}$ for in terleukin evaluation. The concentrations of IFN- $\gamma$, IL-2, IL-6, IL-12, TNF- $\alpha$ and its soluble receptors $R-I, R-I I$ were estimated in non-stimulated and PHA (Sigma, $5 \mu \mathrm{g} / \mathrm{ml}$ ) stimulated culture supernatants using ELISA Endogen kits according to the manufacturer's instructions.

Results: The general pattern of $\mathrm{T}$ cell subpopulation distribution was similar in all analysed groups. Decreased IFN- $\gamma$, IL-12 and increased IL-6 production by lymphocytes after PHA stimulation was found in trimester III in pregnant women with RA as compared to healthy pregnant woman.

Conclusion: The obtained results suggest that in pregnant women with RA the TH1 cell response predominates, contrary to healthy pregnant women with TH2 type functional response. These phenomen a were not observed after delivery.

Key words: Human pregnancy and RA, IFN- $\gamma$, IL-12 and IL-6 production

\section{IL-12, IL-6 and IFN- $\gamma$ production by lymphocytes of pregnant women with rheumatoid arthritis remission during pregnancy}

\author{
Henryk Tchórzewski ${ }^{1,3, C A}$, Grzegorz Krasomski ${ }^{2,4}$, \\ Lidia Biesiada ${ }^{2}$, Ewa Głowacka', \\ Małgorzata Banasik' and Przemysław Lewkowicz ${ }^{1}$
}

${ }^{1}$ Department of Clinical Immunology, and ${ }^{2}$ Department of Gynecology and Obstetrics, Polish Mother's Memorial Hospital-Research Institute, 93-338 kódź, Rzgowska 281/289, ${ }^{3}$ Microbiology, Virology Center of Polish Academy of Sciences, Łódź, Lodowa 106, ${ }^{4}$ Department of Gynecology and Obstetrics Military Medical Academy, kódź, Poland

\footnotetext{
${ }^{\mathrm{CA}}$ Corresponding Author

Tel: 048426451264

Fax: 048426466205

Email: henryt@polbox.com
}

\section{Introduction}

Rheumatoid arthritis (RA) is an autoimmune disorder associated with HLA class II genes responsible for disease progression. ${ }^{1}$ Autoreactive $\mathrm{CD}^{+} \mathrm{CD} 28^{-} \mathrm{T}$ cells undergo clonal expansion in vivo and thus contribute to the pathogenesis of RA. ${ }^{2}$ These cells produce high levels of IFN- $\gamma$ and preferentially express killer cell activating receptors in the absence of inhibitory receptors. ${ }^{3}$ Pregnancy influences the disease severity in woman with rheumatoid arthritis, but no specific factor responsible for improvement has been identified. ${ }^{4}$ The general view exists that in pregnancy the immune relationship between mother and fetus is suppressed. Suppression in pregnancy depends on hormonal factors such as progesterone depressing the immune response and autoimmune diseases, but is effectively compensated by the innate system avoiding infection. The innate immune system components including phagocytes complement system and acute phase proteins are stimulated in pregnancy and may affect the disease. The RA clinical picture is characterised by widespread variability in a pregnant woman: remission, improvement in parameters of disease activity, nevertheless only 16 per cent of pregnant women with RA are in complete remission. ${ }^{5}$ Pregnancy also ameliorates the experimental autoimmune uveitis in mice probably as the effect of selective reduction of Th1 response. ${ }^{6}$ The interaction between the maternal immune system in human pregnancy and some autoimmune diseases depends on the type of dominant immune reaction: remission of RA in pregnant women is connected with exacerbation after delivery but exacerbation of systemic 
lupus erythematosus and ankylosing spondylitis exists in pregnant woman. ${ }^{7}$ We suggest that RA remission in pregnancy is the effect of diminished IFN- $\gamma$ production and misbalance in IL- 6 and IL-12 production, effects which are almost reversed in the postpartum period.

\section{Materials and methods}

\section{Patients}

We have investigated the following groups of patients: 14 healthy nulliparous women, volunteers from the hospital staff, 14 healthy pregnant women, and 6 pregnant women suffering from rheumatoid arthritis (Table 1). All patients were 20-30 years old (mean 24.7). Pregnant women were observed from trimester I of pregnancy to 6 weeks after delivery (at that time a few refused). At the time of study and for at least 4 weeks before no patient had clinical signs of active infection. All patients with RA fulfilling the revised American Rheumatology Association (ARA) criteria ${ }^{8}$ were included in this study.

\section{Methods}

The venous blood samples were collected between 8-9 am to Vacutainer probes on Heparin $10 \mathrm{U} / \mathrm{ml}$, all tests were performed within $2 \mathrm{~h}$ after withdrawal. Peripheral blood lymphocytes were isolated on Gradisol gradient ${ }^{9}$ and analysed immediately after withdrawal or after $72 \mathrm{~h}$ culture $\left(2 \times 10^{6}\right.$ cells $\left./ \mathrm{ml}\right)$ in RPMI medium supplemented with $10 \%$ foetal calf serum, glutamine, and antibiotics. PHA (Sigma) $5 \mu \mathrm{g} / \mathrm{ml}$ lymphocytes $\left(1 \times 10^{6} / \mathrm{ml}\right)$ were cultured in $\mathrm{CO}_{2}$ incubator on 0.2 Nunc plates in RPMI medium supplemented with $10 \%$ of fetal calf serum (Hungarpol). The cultures were terminated after $72 \mathrm{~h}$, supernatants stored at $-72^{\circ} \mathrm{C}$ for interleukin evaluation. Measurements of IFN- $\gamma$, IL-2, IL-6, IL-12, TNF- $\alpha$ and it soluble receptors R-I, R-II were performed in non-stimulated and PHA stimulated culture supernatants using ELISA Endogen kits according to the manufacturer's instructions.

The lymphocytes submitted to subpopulation analyses were washed and incubated with $10 \%$ solution

Table 1. Characteristics of the women investigated

\begin{tabular}{|c|c|c|c|}
\hline Group & $n$ & $\begin{array}{c}\text { Age } \\
\text { (years) }\end{array}$ & Clinical and laboratory tests \\
\hline Healthy & 14 & $20-30$ & $\begin{array}{l}\text { No signs of disease. } \\
\text { Blood and urine normal }\end{array}$ \\
\hline Pregnant & 14 & $19-31$ & $\begin{array}{l}\text { No signs of disease. } \\
\text { Blood and urine normal }\end{array}$ \\
\hline $\begin{array}{l}\text { Pregnant } \\
\text { with RA }\end{array}$ & 6 & $20-30$ & $\begin{array}{l}\text { RF positive in } 4 \text { patients, } \\
\text { blood and urine normal, } \\
\text { sedimentation rate increased } \\
\text { no joint and muscle pain }\end{array}$ \\
\hline
\end{tabular}

of mouse serum at room temperature. They were then incubated with FITC conjugated anti CD3, CD4, CD8, and $\mathrm{CD} 19$ mo $\mathrm{Ab}$ respectively, then washed and fixed with 1\% paraformaldehyde solution. CD4 RO, RA and CD8 RO, RA antigen expression was evaluated by a double staining procedure and labeled cells were fixed in $1 \%$ paraformaldehyde and analyzed using a Becton-Dickinson cytometer. The results are expressed as the percentage of gated double positive cells for antibodies used versus all lymphocytes.

\section{Statistical assessments}

The arithmetic means $(X)$ and standard deviations (SD) were calculated for all parameters. Statistical analyses of differences in all of the data were done using the Student- $t$ test using the software program Statistica. Statistical significance was set at $P \leq 0.05$.

The Institute Ethics Committee approved the experimental protocol. All reported investigations have been performed in accordance with the Declaration of Human Rights (Helsinki 1964). Blood samples were generally taken in the course of routine examinations. Informed consent was obtained from all investigated patients.

\section{Results}

The general pattern of $\mathrm{T}$ cell subpopulation distribution was similar in all analysed groups, differences in individual results were usually high therefore the statistical significance could not be calculated for most of the analysed results. The significant differences are outlined as follows: CD19 (B lymphocytes) decreased in pregnant women but significantly increased in pregnant women with RA. These differences disappeared 6 weeks after delivery. The percentage of NK cells in healthy pregnant women decreased from 17.4 in trimester III, 18.5 two days after delivery to 7.06 weeks after delivery; in pregnant women with RA the respective data are $9.4,10.4$ and 11.5 . In vitro culture did not reveal any differences in the pattern of $C D$ antigen distribution.

The ability to produce IL-12, IL-6 and IFN- $\gamma$ by peripheral blood mononuclear cells (PBMC) stimulated with PHA in vitro revealed dynamic changes dependent on pregnancy and the clinical status of the investigated women (Fig. 1A,B,C). IL-12 (Fig. 1A) production by stimulated PBMC of pregnant women with RA was diminished in trimester III of pregnancy, significantly increased 2 days after delivery and normalised 6 weeks after delivery. IL-6 (Fig. 1B) production by stimulated PBMC was generally enhanced in pregnant women suffering from RA. IFN- $\gamma$ (Fig. 1C) production by stimulated PBMC of healthy pregnant woman was enhanced in trimester III and normalised after delivery contrary to PBMC of pregnant woman suffering from RA. Surprisingly, the TNF- $\alpha$ 

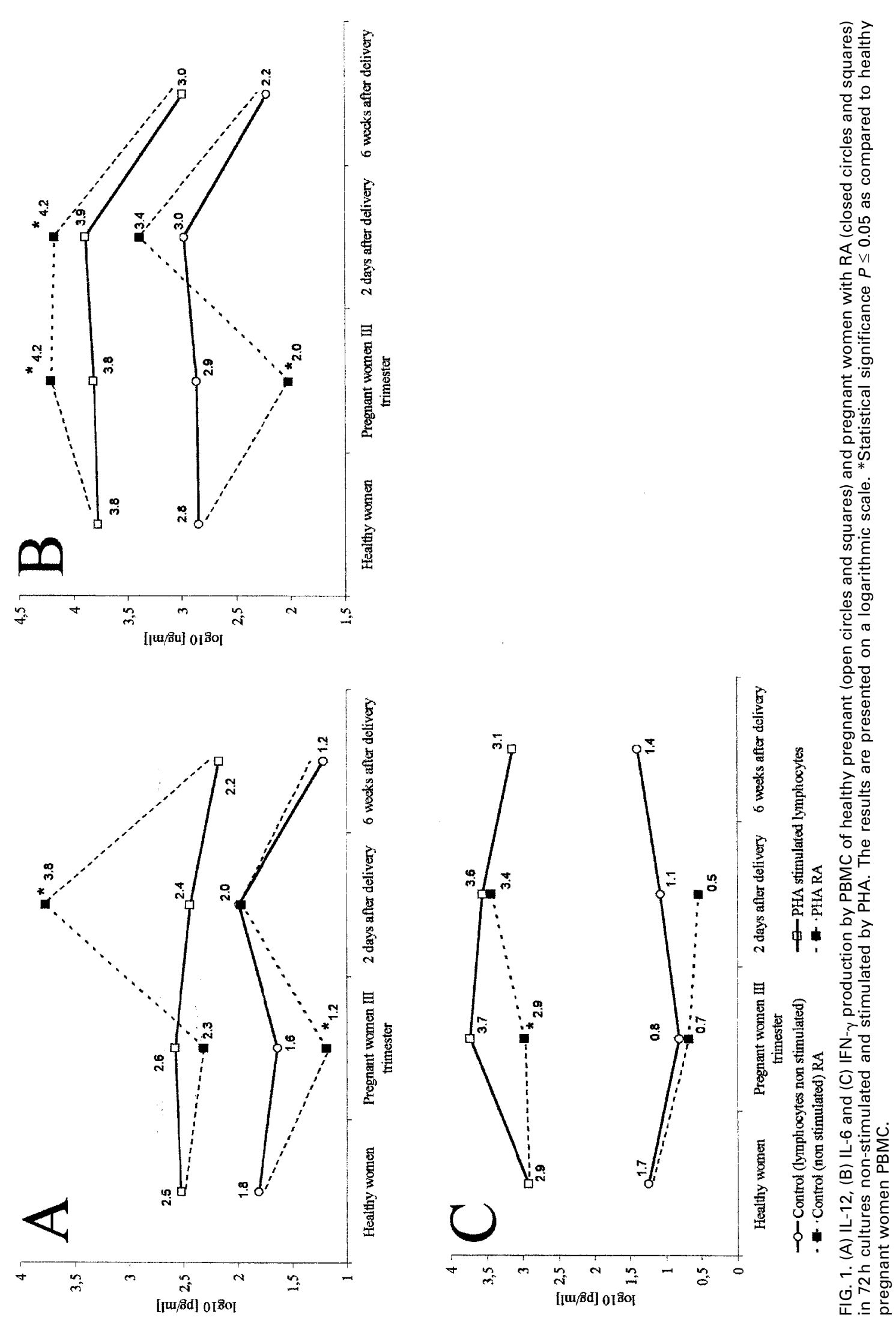
production by stimulated PBMC and TNF- $\alpha$ receptors (R-I and R-II) shedding generally did not reveal significant differences between analysed groups (not shown). The obtained data have suggested a specific regulatory effect in pregnant women with RA on the ability of PBMC to produce some cytokines that affect clinical outcome.

\section{Discussion}

Human pregnancy is compared with tissue transplantation but clearly is not the same. Fetal allograft does not require surgical trauma, it takes place in a unique specialized organ i.e. uterus, grows progressively as the placenta produces hormones and cytokines responsible for suppression of specific immune reactions, occurring during establishment and maintenance of pregnancy. ${ }^{5,10}$ Successful implantation of pregnancy is thought to require the establishment of Th2 cytokines profile of CD4 cells. Progesterone and interleukins 4 and 10 suppress Th1 cytokine responses and this is predicted to be responsible for remission of rheumatoid arthritis during pregnancy. ${ }^{10}$ The central role in the adaptation of suppressed maternal immune system in pregnancy to avoid infection is activation of the innate immune reaction such a complement system, phagocytosis, oxygen burst, IL-12 and chemokines production which is in some way comparable to sepsis. ${ }^{11}$ The increased IFN- $\gamma$ production in human uterine endometrium also plays an important role in modulating immune responses to infectious challenge. IFN- $\gamma$ makes the lymphocytes and neutrophils functionally hyperactive and can exert an autocrine stimulatory effect. ${ }^{11}$ We have observed the significantly enhanced IFN- $\gamma$ production by PBL of pregnant woman after PHA stimulation in vitro. PBL of pregnant women with RA in the same conditions do not produce an enhanced amount of IFN- $\gamma$. Dendritic cells derived from non-obese diabetic mice treated in vitro with IFN- $\gamma$ could protect from diabetes when transferred into susceptible mice. ${ }^{12}$ Hypothetically, the same mechanisms responsible for INF- $\gamma$ production in normal human pregnancy can effectively protect from autoimmune diseases. Diminished IFN- $\gamma$ production in pregnant women with RA may be responsible for disease exacerbation.

IL-6 is required for the development of autoimmune arthritis; IL-6 deficient mice are resistant to the induction of autoimmune disease. ${ }^{13}$ It has been found that IL- 6 is required for disease development in the rodent autoimmune model. IL- 6 pretreated dendritic cells can process autoantigen, present cryptic determinants to $\mathrm{T}$ cells and contribute to the autoimmunity. ${ }^{13}$ Slightly diminished IL-6 production by nonstimulated lymphocytes from pregnant woman with RA and enhanced IL- 6 production after PHA stimulation has proved the possibility that IL- 6 can play a key role in the development of arthritis in these patients. Reduced severity of RA was observed in IL- 6 deficient mice. ${ }^{14}$ The rational explanation of these differences is difficult but could suggest the existence of specific regulatory mechanisms involved in RA during pregnancy. Anti IL-12 and anti TNF-antibodies suppress the progression of murine experimental arthritis. ${ }^{15}$ Blocking the functional IL-12 secretion by dendritic cells inhibits IFN- $\gamma$ production. ${ }^{16}$ The reduced amounts of IL-12 production in vitro by stimulated PBL of pregnant women with RA may result in the generation of Th1 cells. Exogenous IL-12 modified the development of Th cells primed in vitro by dendritic cells, which resulted in the generation of Th1-like cells from naive precursor. However, in vivo dendritic cells are effective inducers of both Th1- and Th2-type cytokines. Our results show that diminished IL-12 generation by lymphocytes of pregnant women with RA in trimester III correlated with enhanced IL-6 production and lowered IFN- $\gamma$ secretion which may result in a Th1 cell-biasing function contrary to the observed down-regulation of Th1 response during normal pregnancy. ${ }^{5}$ McRae et al., ${ }^{16}$ using purified cell lines proved that IL-12 promotes differentiation of CD4 $\mathrm{T}$ cells to produce IFN- $\gamma$. Diminished IL-12 production in trimester III of pregnancy may also result in inhibition of IFN- $\gamma$ production but IL-12 overproduction after delivery does not confirm such a hypothesis and suggests that the mechanism responsible for RA exacerbation in the postpartum period is more complicated. An immunomodulatory effect of non-inherited HLA antigens cannot be excluded. ${ }^{5}$

ACKNOWLEDGEMENTS. This work was supported by the State Committee for Scientific Research Grant No 4 PO5E 08414.

\section{References}

1. Nelson JL, Hughes KA, Smith AG, Nisperos BB, BranchaudAM, Hansen JA. Remission of rheumatoid arthritis during pregnancy and maternal-fetal class II alloantigen disparity. Am J Reprod Im munol 1992: 28: 226-7.

2. Schirmer M, Vallejo AN, Weyand CM, Goronzy JJ. Resistance to apoptosis and elevated expression of Bcl-2 in clonally expanded CD4+CD28-T cells from rheumatoid arthritis patients. J Im m unol 1998: 161: 1018-25.

3. Namekawa T, Snyder MR, Yen JH, Goehring BE, Leibson Pj, Weyand CM, Goronzy JJ. Killer cell activating receptors function as costimulatory molecules on CCD4+CD28null $\mathrm{T}$ cells clonally expanded in rheumatoid arthritis. I Im mu nol 2000: 165(2): 1138-45.

4. SpectorTD, Da Silva JA. Pregnancy and rheumatoid arthritis:an overview. Am J Reprod Im munol 1992: 28: 222-5.

5. Sacks G, Sargent I, Redman C. An innate view of human pregnancy. Im munol To day 1999: 20: 114-8.

6. Barret JH, Brennan P, Fiddler M, Silman AJ. Does rheumatoid arthritis remit during pregnancy and relapse pospartum? Results from a nationwide study in the United Kingdom performed prospectively from late pregnancy. Arthritis Rhe um 1999: 42:1219-27.

7. Katsikis PD, Chu C-Q, Brennan FM, Maini RN, Feldmann M. Immunoregulatory role of interleukin 10 in rheumatoid arthritis. J Exp Med 1994: 179: $1517-27$.

8. Arnett FC, Edworthy SM, Block DJ, Mc Shane DJ, Fries JF, Cooper NS, Healey LA, Kaplan SR, Liang MH, Luthra HS, Medsger TA, Mitchell DM, Neustadt DH, Pinals RS, Schaller JG, Sharp JT, Wilder RL, Hunder GG. The american rheumatism association 1987 revised eriterie for the classification of rheumatoid arthritis. Arthritis Rheum 1988: 31: 315-21.

9. Zeman K, Tchorzewski H, Majewska E, Pokoca L, Pinkowski R. A simple and rapid method of the simultaneous isolation of highly purified lymhocytes and neutrophils from peripheral blood. Im munol Pol 1998: 13: $217-24$. 
10. Wilder RL. Hormones, pregnancy and autoimmune diseas. Ann NY Acad Sci 1998: 840: 45-50.

11. Borden EC. Interferons: pleiotropic cellular modulators. Clin Im munol Im munopathol 1992: 62: 18-24.

12. Shinomiya M, Fazle Akbar SM, Shinomiya H, Onji M. Transfer of dendritic cells (DC) ex vivo stimulated with interferon-gamma (IFN-gamma) downmodulates autoimmune diabetes in non-obese diabetic (NOD) mice. Clin Exp Im munol 1999: 117: 38-43.

13. Drakesmith H, Chain B, Beverly $P$. How can dendritic cells cause autoimmune disease? Im mu nol To day 2000: 21: 214-7.

14. Sasai M, Saeki Y, Ohshima S, Nishioka K, Mima T, Tanaka T, Katada Y, Yoshizaki K, Suemura M, Kishimoto T. Delayed onset and reduced severity of collagen-induced arthritis in interleukin-6-deficient mice. Arthritis Rheum 1999: 42: 1635-43.

15. Butler DM, Malfait AM, Maini RN, Brennan FM, Feldmann M. Anti-IL-12 and antiTNF antibodies synergistically suppress the progression of murine collagen-induced arthritis. Eur J Imm unol 1999: 29: 2205-12.

16. McRae BL, Semnani RT, Hayes MP, van Seventer GA. Type I IFNs inhibit human denritic cell IL-12 production and Th1 cell development. $J$ Immunol 1998: 160: 4298-304.

\section{Received 3 October 2000}

accepted after revision 8 November 2000 


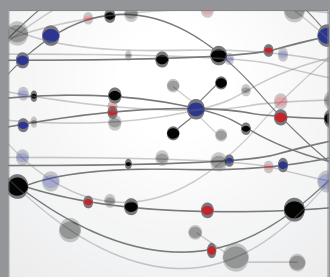

The Scientific World Journal
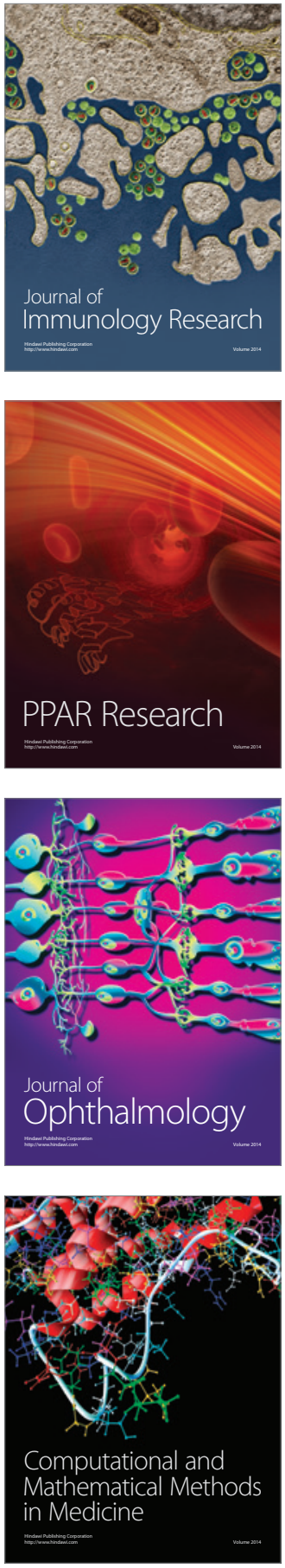

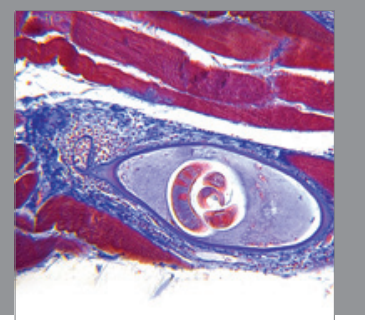

Gastroenterology

Research and Practice
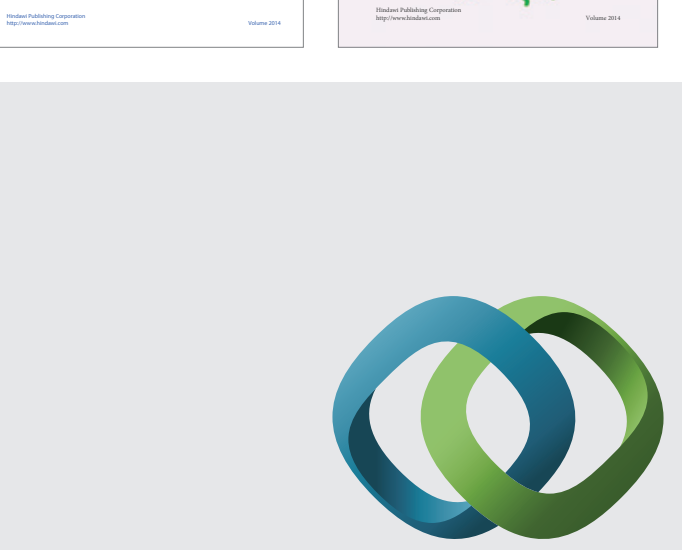

\section{Hindawi}

Submit your manuscripts at

http://www.hindawi.com
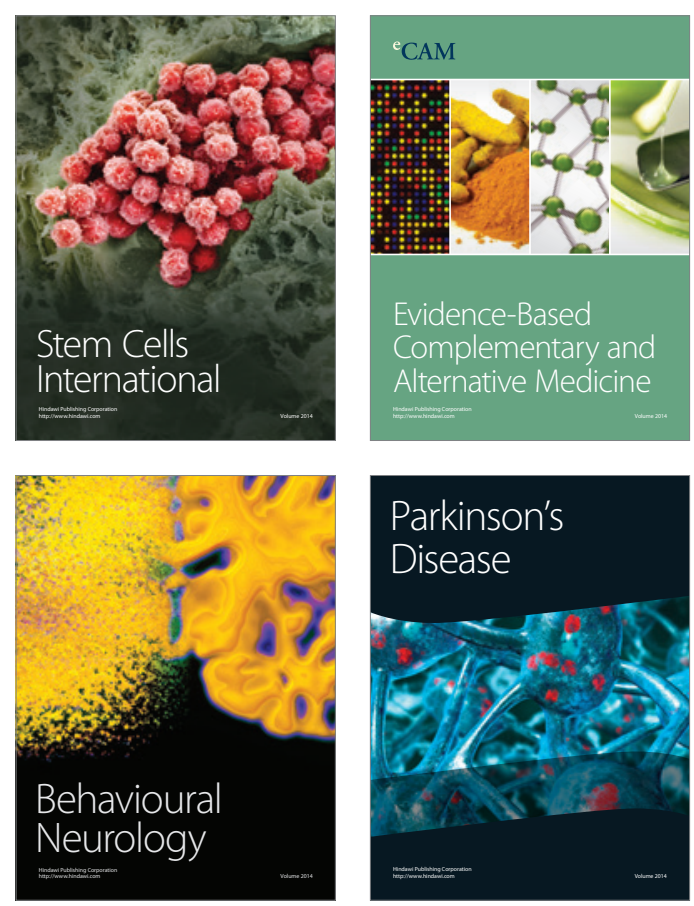

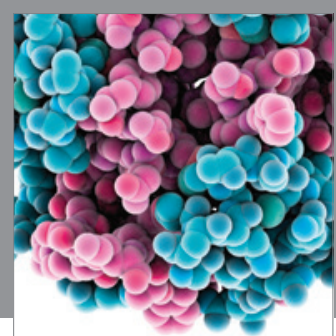

Journal of
Diabetes Research

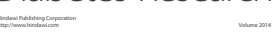

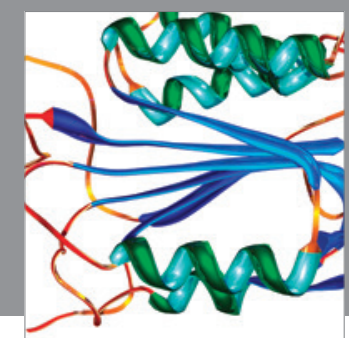

Disease Markers
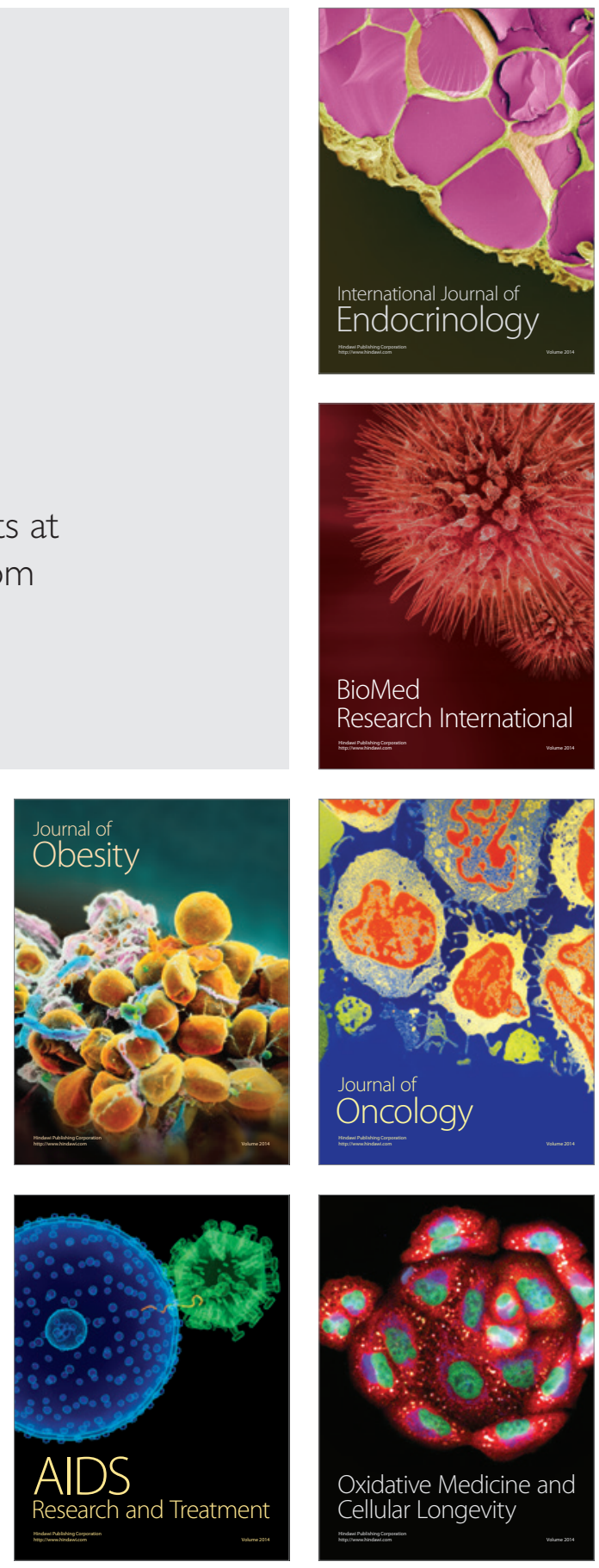